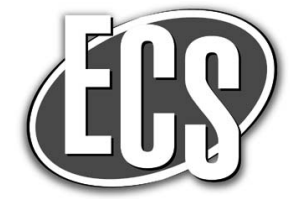

\title{
Corrosion Resistance of Current Collector Materials in Bisamide Based Electrolyte for Magnesium Batteries
}

\author{
Clemens Wall, ,a,b,z Zhirong Zhao-Karger, ${ }^{\text {b }}$ and Maximilian Fichtner ${ }^{a, b}$ \\ ${ }^{a}$ Helmholtz Institute Ulm for Electrochemical Energy Storage (HIU), 89081 Ulm, Germany \\ ${ }^{b}$ Institute of Nanotechnology, Karlsruhe Institute of Technology, 76021 Karlsruhe, Germany
}

\begin{abstract}
The compatibility of Ti, Cr, Ni, Fe, Al, steel type 304, Inconel 625, Hastelloy B and carbon coated current collectors with bisamide based electrolyte for Mg-batteries was investigated. Pitting corrosion of current collectors made from 3d-transition metals and steel type 304 was observed at potentials between $2.2-3.1 \mathrm{~V}$ vs. $\mathrm{Mg} / \mathrm{Mg}^{2+}$. Anodic stability up to $3.8 \mathrm{~V}$ and resistance against corrosion for $48 \mathrm{~h}$ at a potential of $2.5 \mathrm{~V}$ vs. $\mathrm{Mg} / \mathrm{Mg}^{2+}$ and above was found for Inconel 625, Hastelloy B, graphite and carbon coated $\mathrm{Al}$ foil. (C) The Author(s) 2014. Published by ECS. This is an open access article distributed under the terms of the Creative Commons Attribution Non-Commercial No Derivatives 4.0 License (CC BY-NC-ND, http://creativecommons.org/licenses/by-nc-nd/4.0/), which permits non-commercial reuse, distribution, and reproduction in any medium, provided the original work is not changed in any way and is properly cited. For permission for commercial reuse, please email: oa @electrochem.org. [DOI: 10.1149/2.0111501eel] All rights reserved.
\end{abstract}

Manuscript submitted October 9, 2014; revised manuscript received November 10, 2014. Published November 18, 2014.

Recently Mg batteries have gained large interest due to the high theoretical energy density of $\mathrm{Mg}\left(2233 \mathrm{mAh} \mathrm{g}^{-1}\right.$ and $3832 \mathrm{mAh} \mathrm{cm}^{-3}$, respectively) but also because of the comparable low price, high abundance and the non-toxic properties of $\mathrm{Mg} .{ }^{1,2}$ In contrast to metallic $\mathrm{Li}$, no dendrite formation has been observed during electrochemical cycling of Mg., ${ }^{3,4}$ Thus, the technical application of metallic Mg anodes for secondary batteries with liquid electrolyte is not hampered by safety concerns as they exist for metallic Li. As the energy density of a battery is determined by the capacity of the electrode materials and by the potential difference between the anode and the cathode, both should be as high as possible. However, high operation potentials increase the driving force for oxidative decomposition of the electrolyte as well as for corrosion of the current collector at the cathode. Anodic stabilities of electrolytes exceeding $3 \mathrm{~V}$ vs. $\mathrm{Mg} / \mathrm{Mg}^{2+}$ have been demonstrated recently. ${ }^{5-7}$ However, until now all electrolytes for $\mathrm{Mg}$ batteries with good electrochemical performance (i.e. large voltage window, compatibility with metallic $\mathrm{Mg}$ and high ionic conductivity) contain chlorine, which was found to cause severe corrosion of current collectors made from $\mathrm{Cu}, \mathrm{Al}, \mathrm{Ti}$ and stainless steel. ${ }^{2,8,9}$

Recently we developed a synthesis for bisamide based electrolytes with unprecedented anodic stability by reaction of magnesiumbis(hexamethyldisilazide) $\left[(\mathrm{HMDS})_{2} \mathrm{Mg}\right]$ with $\mathrm{AlCl}_{3}$ in different aprotic solvents, which are compatible with sulfur cathodes. ${ }^{5,10}$ In order to utilize such electrolytes for magnesium batteries, we have now studied the corrosion behavior of various metals and steels and investigated if corrosion can be mitigated by a carbon coating.

\section{Experimental}

Chronoamperometry and linear sweep voltammetry of current collectors was conducted vs. $\mathrm{Mg}$ foil, (Goodfellow, $99.99 \%$ ) in twoelectrode PTFE Swagelok cells. A PTFE ring (inner diameter $5 \mathrm{~mm}$, thickness $2 \mathrm{~mm}$ ) was used to spatially separate the current collector from the Mg-foil which served as counter and quasi reference electrode. The current collectors were laser-cut or punched from Fe (Sigma Aldrich, 99.9\%), Ni (Sigma Aldrich, 99.9\%), Ti (Sigma Aldrich, 99.9\%), Cr (Goodfellow, 99.99\%) Al (Alfa Aesar, 99.9998\%), carbon coated Al (Showa Denko), Inconel 625 (Ni 61\%, Cr 22\%, Fe $<5 \%$, Mo 9\%, Goodfellow), Hastelloy B (Ni 62\%, Mo 27\%, Fe 5\%, Cr $0.8 \%, \mathrm{Mn} 0.6 \%$, Si $0.5 \%$, Goodfellow) and stainless steel type 304 (Fe, Ni $18 \%, \mathrm{Cr} 8 \%, \mathrm{Mn}<2 \%, \mathrm{Si}<1 \%$ ) foils. Prior to the electrochemical experiments, the foils were abraded with successive grades of sand papers down to 4000 grit to achieve a mirror finish, followed by ultrasonic cleaning in 2-propanol and acetone. The polishing and cleaning steps were conducted in air. After drying, the current collectors were transferred into an Ar-filled glove box, where the test cells were assembled. The stainless steel rods of the positive terminals of the test cells were protected from the contact with electrolyte by graphite foil discs. A $1 \mathrm{M}$ solution of (HMDS) ${ }_{2} \mathrm{Mg}-\mathrm{AlCl}_{3}$ (molar ratio $1: 2$ ) in tetraglyme was prepared as described elsewhere ${ }^{5}$ and used as electrolyte. Before the electrochemical tests, the cells were allowed to rest for $12 \mathrm{~h}$. Linear sweep voltammetry and chronoamperometry were performed with a Biologic VMP3 potentiostat. Onset potentials of anodic current were determined at a current density of $0.025 \mathrm{~mA} / \mathrm{cm}^{-2}$. Afterward, the cells were disassembled and the current collectors were rinsed with acetone to remove residual electrolyte. Scanning electron microscopy (SEM) was performed with a Zeiss LEO 1530 at $20 \mathrm{keV}$.

\section{Results and Discussion}

To investigate the compatibility of 3d-transition metal current collectors with (HMDS) ${ }_{2} \mathrm{Mg}-\mathrm{AlCl}_{3} /$ tetraglyme electrolyte, linear sweep voltammetry was performed (Figure 1a). The anodic current at the Pt working electrode above $3.6 \mathrm{~V}$ indicates the anodic decomposition of the electrolyte. For the transition metal current collectors, anodic currents were observed at significantly lower potentials. The onset potentials of anodic current was lowest for $\mathrm{Al}(2.2 \mathrm{~V})$, where an additional anodic peak at $1.8 \mathrm{~V}$ was observed. For $\mathrm{Cr}$, $\mathrm{Ti}$ and $\mathrm{Fe}$ comparable stability of $2.8-2.9 \mathrm{~V}$ was observed, whereas a slightly higher stability of $3.1 \mathrm{~V}$ was observed for Ni. The anodic currents below the decomposition potential of the electrolyte on Pt working electrodes have been reported for Mg electrolytes with similar composition before and were attributed to pitting corrosion of the current collectors. ${ }^{8,9,11,12}$ This observation was confirmed by investigation of the current collectors after the polarization by SEM, showing that the surface of the current collectors were covered with corrosion pits which is shown exemplarily for a Ni current collector in Figure 1b.

Motivated by previous reports of high anodic stability of Grignard based electrolytes on glassy carbon and carbon coated $\mathrm{Ti}$ working electrodes, ${ }^{9}$ the corrosion resistance of carbonaceous surfaces was investigated by linear sweep voltammetry and chronoamperometry.

As shown in Figure 2a, a high anodic stability beyond $3 \mathrm{~V}$ was observed for a graphite current collector in linear sweep voltammetry. During chronoamperometry at a potential of $2.5 \mathrm{~V}$ vs. $\mathrm{Mg} / \mathrm{Mg}^{2+}$ no increase of the current density was measured during $48 \mathrm{~h}$, confirming the good stability of the graphite current collector in the electrolyte.

The brittleness of graphite and glassy carbon very likely would prevent their application as current collectors for commercial batteries. Thus, we tested if a carbon coating can protect Al-foil against corrosion in bisamide based electrolyte. In linear sweep voltammetry it was found that the onset of anodic current for the carbon coated Al 
(a)

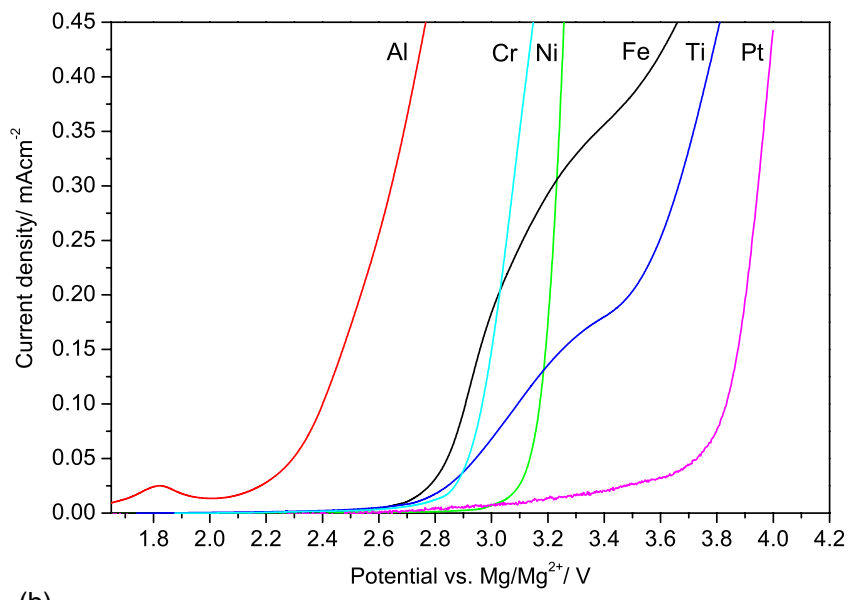

(b)

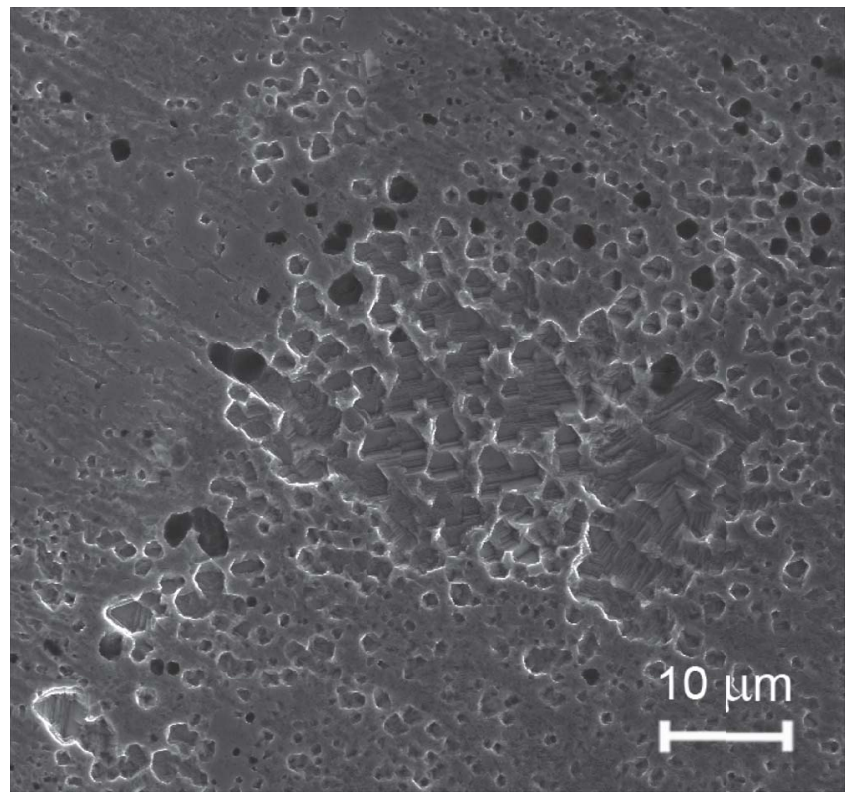

Figure 1. (a) Linear sweep voltammograms of metals in bisamide based electrolyte. (b) SEM micrograph of a Ni current collector after linear sweep voltammetry.

foil occurred at a potential that is approximately $0.8 \mathrm{~V}$ more noble than the uncoated foil (Figure 2a). Furthermore, a much lower current density of $20-50 \mu \mathrm{A} / \mathrm{cm}^{2}$ was observed during chronoamperometry at $2.5 \mathrm{~V}$ vs. $\mathrm{Mg} / \mathrm{Mg}^{2+}$ for the carbon coated Al-foil (Figure 2b). Thus, the carbon coating efficiently protected the Al-foil against corrosion, which was further confirmed by SEM, where no damage of the surface of the carbon coated $\mathrm{Al}$ after chronoamperometry was observed.

Alloys can have advantageous properties over pure metals in terms of mechanical strength and price and some alloys show excellent corrosion resistance in corrosive environments. ${ }^{13}$ Thus, the corrosion resistance of stainless steel type 304, Inconel 625 and Hastelloy $\mathrm{B}$ in the bisamide based electrolyte was investigated. As shown in Figure $3 \mathrm{a}$, notably higher anodic stabilities of $3.3 \mathrm{~V}$ and $3.8 \mathrm{~V}$ were observed for Inconel and Hastelloy B by linear sweep voltammetry, respectively, while an anodic current was observed above $2.9 \mathrm{~V}$ vs. $\mathrm{Mg} / \mathrm{Mg}^{2+}$ for stainless steel. The strong rise of the current density in the chronoamperometry of the stainless steel current collector at $2.5 \mathrm{~V}$ vs. $\mathrm{Mg} / \mathrm{Mg}^{2+}$ (Figure 3b) can be attributed to deterioration of the passivation film, which ultimately led to pitting corrosion after an incubation time. ${ }^{14}$ In contrast, only very low current densities were
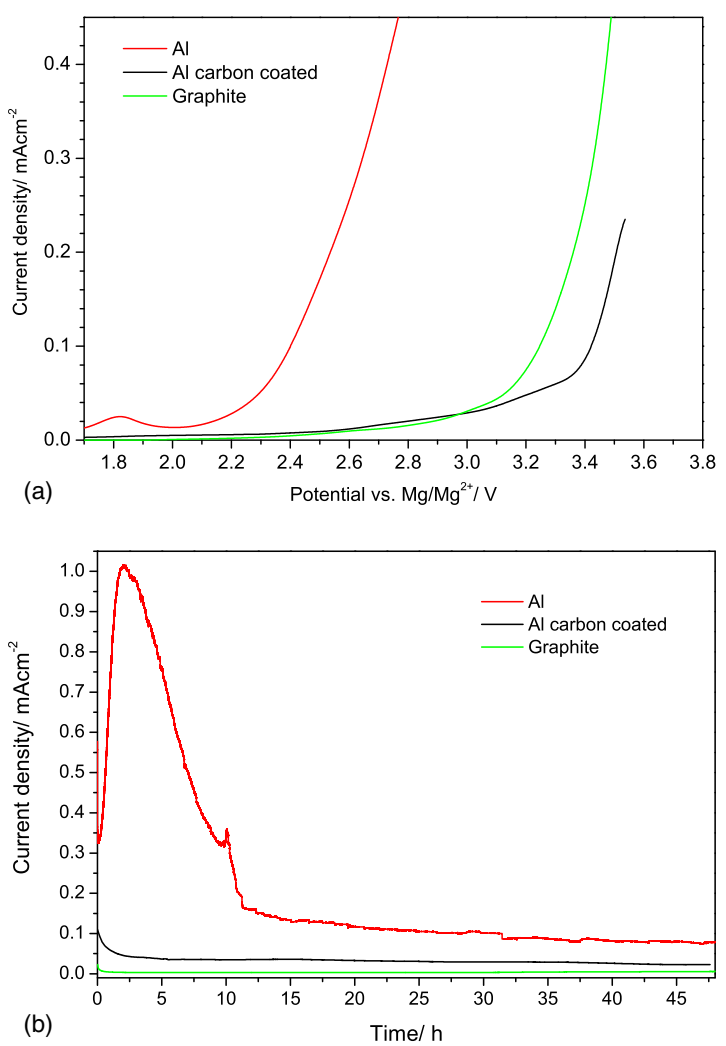

Figure 2. Linear sweep voltammograms (a) and chronoamperograms (b) at $2.5 \mathrm{~V}$ vs. $\mathrm{Mg} / \mathrm{Mg}^{2+}$ of $\mathrm{Al}$, carbon-coated $\mathrm{Al}$ and graphite in bisamide based electrolyte
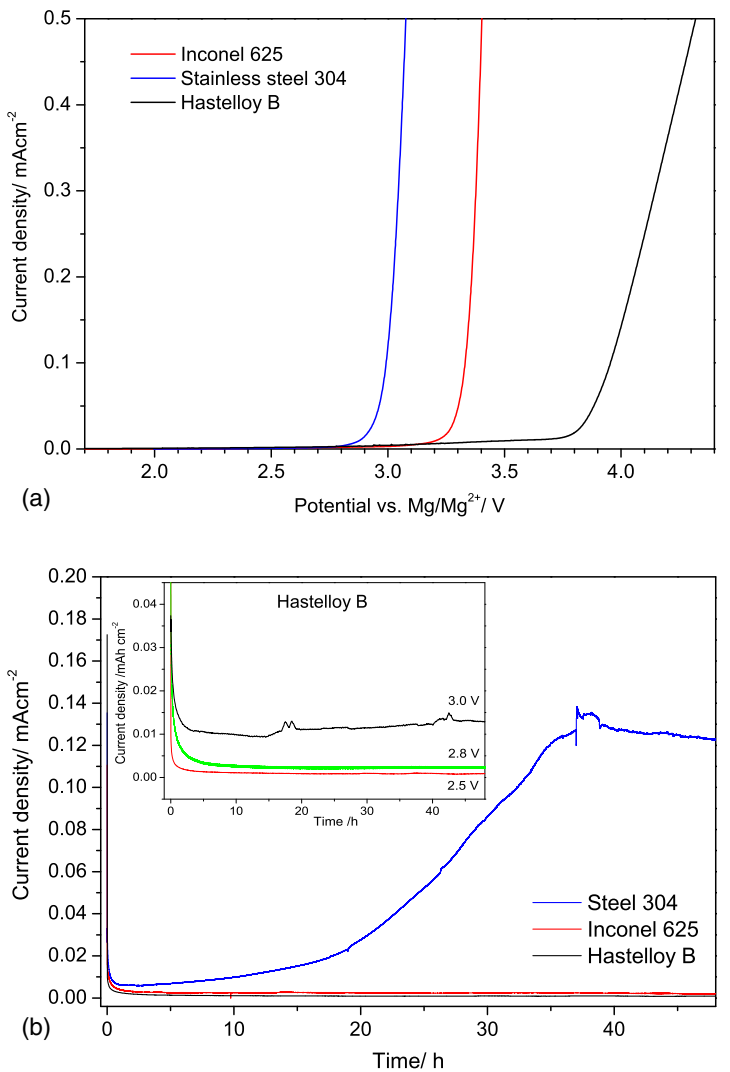

Figure 3. Linear sweep voltammograms (a) and chronoamperograms (b) of steels in bisamide based electrolyte. The inset in figure (b) shows chronoamperograms of Hastelloy B at different potentials. 
(a)

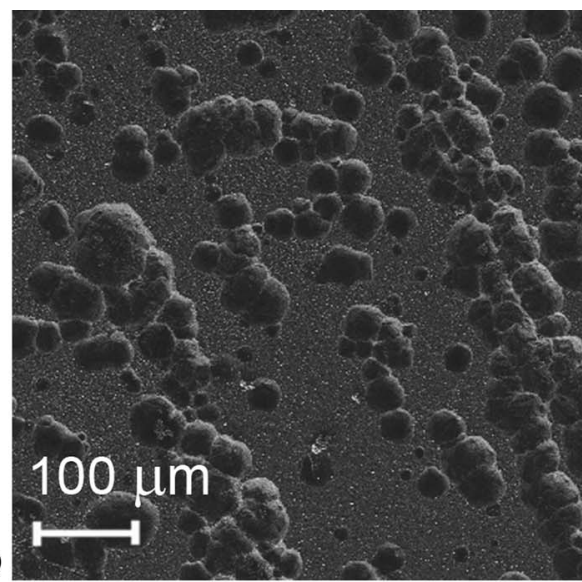

(b)

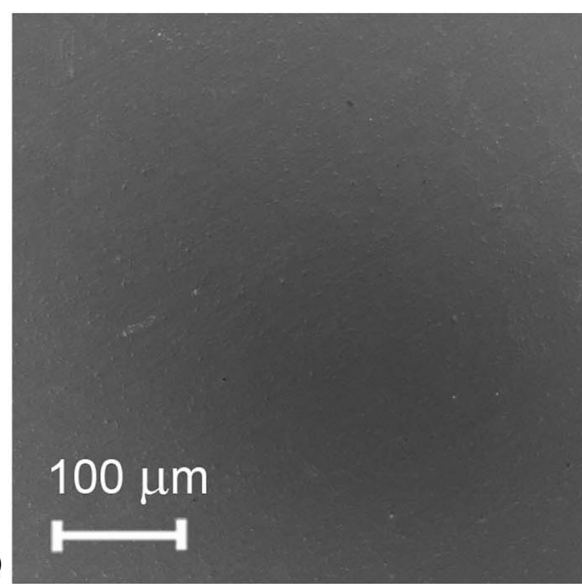

(c)

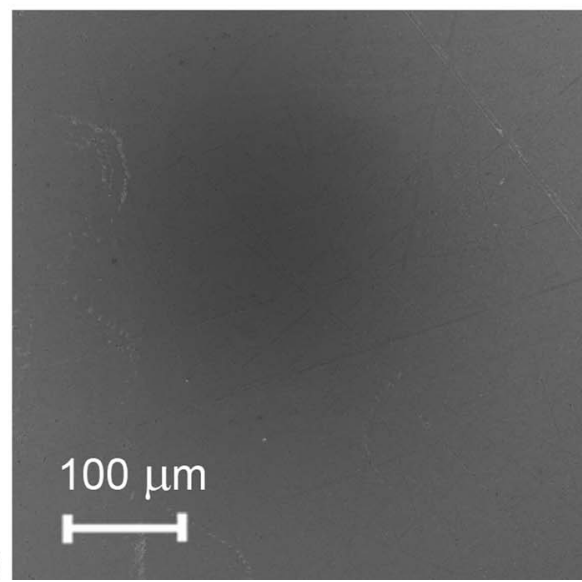

Figure 4. SEM micrographs of (a) steel type 304, (b) Hastelloy B, (c) Inconel 625 after polarization to $2.5 \mathrm{~V}$ vs. $\mathrm{Mg} / \mathrm{Mg}^{2+}$ for $48 \mathrm{~h}$. observed in the case of Inconel 625 and Hastelloy B at $2.5 \mathrm{~V}$ vs. $\mathrm{Mg} / \mathrm{Mg}^{2+}$. Even at 2.8 and $3 \mathrm{~V}$ vs. $\mathrm{Mg} / \mathrm{Mg}^{2+}$ comparably low current densities were observed during chronoamperometry for Hastelloy B, as shown in the same figure. The low current densities indicate that stable passivation layers on the surface of Inconel 625 and Hastelloy B protect them against corrosion similar to what was found on Mo current collectors in all-phenyl complex electrolyte. ${ }^{12}$ It has been shown that $\mathrm{Cr}$ and Mo influence the passivation behavior of steels in chloride containing environments. ${ }^{15,16}$ However, further investigations are needed to clarify whether the same mechanisms are responsible for the corrosion resistance of Hastelloy B and Inconel 625 in the bisamide based electrolyte.

The analysis of the surface of the steels after polarization to $2.5 \mathrm{~V}$ for 48 hours by SEM confirmed the good corrosion resistivity of Inconel 625 and Hastelloy B in the electrolyte (Figure 4). While the surface of steel type 304 was covered by corrosion pits after the polarization for $48 \mathrm{~h}$, the surface of Inconel 625 and Hastelloy B was intact and no signs of corrosion were observed.

\section{Conclusions}

Corrosion of $\mathrm{Ti}, \mathrm{Fe}, \mathrm{Cr}, \mathrm{Ni}$ and $\mathrm{Al}$ current collectors in bisamide based electrolyte was indicated by an onset of anodic current in linear sweep voltammetry at potentials between $2.2-3.1 \mathrm{~V}$ vs. $\mathrm{Mg} / \mathrm{Mg}^{2+}$. Severe pitting of the current collectors was observed by SEM investigations after the polarization. In a $48 \mathrm{~h}$ test of carbon-coated $\mathrm{Al}$, no hints for corrosion were found and the anodic stability was increased up to $3 \mathrm{~V}$ vs. $\mathrm{Mg} / \mathrm{Mg}^{2+}$. Furthermore, excellent corrosion resistance was observed for Inconel 625 and Hastelloy B in terms of anodic stability (3.3 and $3.8 \mathrm{~V}$, respectively) and stability at $2.5 \mathrm{~V}$ and $2.8 \mathrm{~V}$ vs. $\mathrm{Mg} / \mathrm{Mg}^{2+}$, respectively, for $48 \mathrm{~h}$.

\section{References}

1. D. Aurbach, I. Weissman, Y. Gofer, and E. Levi, Chem. Rec., 3, 61 (2003).

2. J. Muldoon, C. B. Bucur, A. G. Oliver, T. Sugimoto, M. Matsui, H. S. Kim, G. D. Allred, J. Zajicek, and Y. Kotani, Energy Environ. Sci., 5, 5941 (2012).

3. F. Orsini, A. du Pasquier, B. Beaudouin, J.M. Tarascon, M. Trentin, N. Langenhuizen, E. de Beer, and P. Notten, J. Power Sources, 81-82, 918 (1999).

4. J. O. Besenhard and M. Winter, Chemphyschem, 3, 155 (2002).

5. Z. Zhao-Karger, X. Zhao, O. Fuhr, and M. Fichtner, RSC Adv., 3, 16330 (2013).

6. Y. S. Guo, F. Zhang, J. Yang, F. F. Wang, Y. NuLi, and S. I. Hirano, Energy Environ. Sci., 5, 9100 (2012).

7. O. Mizrahi, N. Amir, E. Pollak, O. Chusid, V. Marks, H. Gottlieb, L. Larush, E. Zinigrad, and D. Aurbach J. Electrochem. Soc., 155, A103 (2008).

8. D. Lv, T. Xu, P. Saha, M. K. Datta, M. L. Gordin, A. Manivannan, P. N. Kumta, and D. Wang J. Electrochem. Soc., 160, A351 (2012).

9. S. Yagi, A. Tanaka, Y. Ichikawa, T. Ichitsubo, and E. Matsubara, J. Electrochem. Soc., 160, C83 (2013)

10. Z. Zhao-Karger, X. Zhao, D. Wang, T. Diemant, R. J. Behm, and M. Fichtner, $A d v$. Energy Mater, (2014).

11. J. Muldoon, C. B. Bucur, A. G. Oliver, J. Zajicek, G. D. Allred, and W. C. Boggess, Energy Environ. Sci., 6, 482 (2013).

12. Y. Cheng, T. Liu, Y. Shao, M.H. Engelhard, J. Liu, and G. Li, J. Mater. Chem. A, 2, 2473 (2014).

13. G. S. Frankel, J. Electrochem. Soc., 145, 2186 (1998).

14. S. S. Abdel Rehim, H. H. Hassan, and M. A. Amin, Corros. Sci., 46, 1921 (2004)

15. H. Ogawa, H. Omata, I. Itoh, and H. Okada, Corrosion, 34, 2 (1978)

16. M. Urquidi and D. D. Macdonald, J. Electrochem. Soc., 132, 555 (1985). 